\title{
Vulnerability of water source selected for emergency water supply in the Czech Republic
}

\author{
E. Bakoš ${ }^{1}$, F. Božek ${ }^{1}$, A. Bumbová ${ }^{1}$, J. Dvořák ${ }^{2} \&$ M. Č́slavský ${ }^{3}$ \\ ${ }^{I}$ Department of Population Protection, University of Defence, \\ Brno, Czech Republic \\ ${ }^{2}$ Language Training Centre, University of Defence, Brno, Czech Republic \\ ${ }^{3}$ GEOtest, a.s., Brno, Czech Republic
}

\begin{abstract}
This paper deals with the semi-quantitative vulnerability assessment of the elements of hydrogeological structure and technological equipment of the source of ground water, which has been selected for the emergency supply of the population with drinking water. The vulnerability assessment stems from the application of the register of hazards and a potential threat to individual water source elements within each type of hazard. The semiquantitative assessment used the former general register of vulnerability together with the index assessment of vulnerability of source elements depending on the range of impact, i.e. its disturbance, damage, or destruction due to the activation of the source of the hazard. The outcome of water source vulnerability assessment was the assignment of a vulnerability index to each potential type of hazard and each threatened element. The acquired vulnerability indexes will become a basis for a source damage/destruction risk assessment in the case of each vulnerability/hazard pair and the following identification of critical risks and a source classification for the needs of crisis planning.

Keywords: hazard, hydrogeological structure, elements, criticality, index, sensitivity, water source, vulnerability.
\end{abstract}

\section{Introduction}

With regard to the fact that a human being without water survives for only three to six days, the water supply is of even higher significance especially under crisis situations, in which the supply of water to population from water supply systems 
is either limited or totally broken. Such cuts may be either local or global, depending on the extent of crisis. The supply of water to population may efficiently be solved by operating the alternative sources, which are the structures of ground waters [1].

At present we cannot rely upon the assumptions that the risks of crises, accompanied with partial or total failure of public system of supplying population with drinking water, are low. Therefore it is efficient to have a list of sources of ground waters incorporated into the crisis plans. Such sources may be classified on the basis of risk analysis and utilized in the case of crises. Inseparable part of risk analysis is the assessment of vulnerability of each element of hydrogeological structure and technological equipment of water source in relation to each identified natural and anthropogenic hazard [2].

The contribution is focused on possible procedure in the semiquantitative assessment of vulnerability of individual elements of water source on the basis of elaborated point index of vulnerabilities and the register of hazards [2] for the selected water source earmarked for the emergency supply of population with drinking water.

\section{The analysis of current state}

The large extent disturbance of drinking water supply is a crisis situation, which may almost be excluded, if it does not occur in the consequence of another emergency event [3]. The drinking water supply may be disturbed anywhere in the Czech Republic, if it is caused by an ordinary breakdown of water supply system. Such a cut off in supply is managed by a particular water supply and sewage system entity, which organizes an emergency supply of population with drinking water in the affected areas according to a particular model plan for emergency water supply [3]. However, if an emergency event causes the large extent cut off in drinking water supply, it will be solved, besides other measures being taken, by the emergency drinking water supply [3]. Such an emergency supply may be supported only by legislation, i.e. by declaring the state of crisis. In the past the crisis situation connected with the large extent disturbance of drinking water supply was managed as a part of complex emergency supply of affected population during the floods in the Czech Republic in 1997 and 2002. There are historical lessons learned that the crisis situation caused by the massive disturbance of drinking water supply is considered to be of territorial character and is usually connected with the occurrence of another emergency event [3].

The technical support to the emergency water supply in the Czech Republic is provided by regional and municipal authorities through the Emergency water supply service. Depending on the type of disturbance of drinking water supply it is possible to use mainly the following [4]:

a) non-damaged water supply systems or their parts;

b) non-damaged isolated water intake structures, mainly wells;

The emergency supply of drinking water starts within 5 hours after the state of crisis is declared [3]. The requirements for water quality in the conditions of 
emergency supply may be different from the requirements for the quality of drinking water for one month as a maximum [5]. It is possible to use the U.S. EPA document in order to orientate quickly, whether the concentration of individual contaminants in supplied water is acceptable. The U.S. EPA document states health advisories for 1-day and 10-day exposure of a child weighing $10 \mathrm{~kg}$ to the range of 210 contaminants, including inorganic anions and cations, organic substances and significant radionuclides [6].

For emergency supply it is the matter of priority to assess the capability of water supply system to supply water. It is also recommended to use the ground water sources, mainly the vertical water intake structures, established and equipped for the intake of ground waters of deeper circulation, and if need be, also the horizontal and combined water intake structures [7].

The accumulation of surface waters in water reservoirs and watercourses cannot be recommended for emergency supply due to its high vulnerability. The sources of surface waters should be used only exceptionally and only in justified cases. It is not suitable to use all hydrogeological structures for the needs of crisis management, either, because they have different hydrogeological conditions, hydrological regime, water quality, accessibility and yield. Besides that, they are threatened by a number of hazards with various vulnerability of individual elements of technological sources [2].

The risk quantification requires the frequency of activation of each identified source and also the vulnerabilities of parts of hydrogeological structure and individual technological elements of ground water source. Generally the vulnerability of water source may be defined as a property, characterized by its susceptibility to damage or destruction due to its low resistance to hazard depending on the character of load and the time of exposure [8]. The vulnerability assessment of ground water sources is a very complex and demanding task. The semiquantitative index method is used for such an assessment [9]. The above mentioned method has been modified by our group for the needs of assessing the vulnerabilities of the threatened elements of the source of ground water [2].

The point vulnerability index has been built together with its verbal definition for each threatened element of hydrogeological structure and technological equipment of water source in relation to the intensity of hazard impact [2]. The procedure of implementing the proposed vulnerability index for the selected source of ground water suitable for emergency supply is described in the text below. The necessary prerequisite of implementing the proposed procedure was the former elaboration of the register of hazards and the identification of threatened elements of the assessed source, which are specific for each water source and each hazard [10].

\section{Applied methods}

The method of "Fault Tree Analysis" has been used for building the general register of vulnerabilities [2], based on a systematic retrospective analysis of 
events while employing the chain of causes, which could lead to the selected topevent, in combination with the "What if" method $[11,12]$.

The elements of hydrogeological structure and technological equipment of water sources, potentially affected by the activation of a particular source of hazard, have been identified at three joint meetings of seven experts and through their brainstorming with two iterations [13]. The asking of questions leading to the identification of threatened elements of water sources was not systematized in this case.

The vulnerability index determined in points for each identified pair of hazard/vulnerability of the assessed water source has used the former definitions of point indexes of vulnerability of individual elements of hydrogeological structure and technological equipment of water sources [2]. The point indexation of vulnerability of individual water source elements for each identified hazard has also been made through brainstorming, similarly to the identification of threatened water source elements.

\section{Outcomes and discussion}

The identified threatened elements of emergency ground water sources may be divided into a hydrological structure and technological equipment for the intake, treatment and distribution of ground water [2].

The following elements may be threatened in the hydrogeological structure of water source:

a) Hydrogeological Conditions (HGC);

b) Hydrological Regime (HR);

c) Ground Water Quality (GWQ).

The following threatened elements have been identified in the technological equipment of water source:

a) Hydrogeological Conditions (HGC);

b) Water Intake Structures (WIS);

c) Water Treatment Plant (WTP);

d) Distribution system (DS);

e) House Connections and Water Distribution System (HCWDS).

Only the hazards to intake structures and water treatment plant have been monitored within the above mentioned subsystems, because they are located mostly at the places of exploited hydrogeological structure. The distribution system and terminal connections, including house connection and water distribution systems are usually located quite far from the exploited hydrogeological structure and are not closely connected with the source itself.

When assessing the $R_{j, i}$ risk of contamination, damage, or destruction of $i$-element of water source resulting from the activation of $j$-source of hazard it is necessary to start from the register of potential hazards to the individual elements of hydrological structure and technological equipment of the assessed source. The $R_{j, i}(\tau)$ risk in the given time $\tau$ is calculated according to the equation (1), 
where $P_{j}(\tau)$ represents the value of point index related to the probability of activation of $j$-source of hazard in time $\tau$, and $V_{j, i}(\tau)$ is the value of point index of vulnerability of $i$-element of water source to $j$-hazard in the same time $\tau$.

$$
R_{j, i}(\tau)=P_{j}(\tau) \times V_{j, i}(\tau)
$$

It results from the equation (1) that besides knowing the frequency of activation of $j$-source of hazard, expressed on an index scale [8] it is also necessary to know the quantification of vulnerability $V_{j, i}$ in the form of index assessment of each $i$-element of water source in relation to each identified $j$ hazard at the time $\tau$. Therefore it was necessary to assign the point value of vulnerability index to each hazard/vulnerability pair of the assessed water source.

Brainstorming helped to index the vulnerability while employing the data presented in Table 1 concerning the former verbal assessment, which defined the values of indexes in points in relation to the level of disturbance, damage, or destruction of the considered elements of water source [2].

It is also necessary to accept general and natural conditions in the broad surrounding of the assessed water source with focus not only on its protective zone, but also the infiltration area. Historical data have been used as well.

The general data include mainly the geographic specification, the former exploitation of territory, the characteristics of area settlement and possibly the property rights. As far as the natural conditions are concerned, mainly the following aspects have been specified and assessed: the character of the territory and its relation to the larger vicinity, terrain morphology, orographic data, climatic, geological, hydrogeological and hydrological conditions, geochemical data on the area and, last but not least, the protection of nature and landscape. The former emergency events and the range of damage to the assessed elements of water source have also been taken into consideration.

The potential hazards identified for the monitored water source are the hazards from the group of natural disasters caused by atmospheric and geologic changes and also by other impacts. Technological hazards include fires of anthropogenic origin as well as the hazards caused by common activities in husbandry and forestry. Ecological burdens near the source and its infiltration area have not been discovered [10].

\subsection{Storms and electric effects}

Technical equipment of the source of emergency water supply is vulnerable to storms and electric effects. The strike of lightning may cause either the fall-out of electric current in the armature chamber and water treatment plant or the damage or even destruction of electronic equipment. 


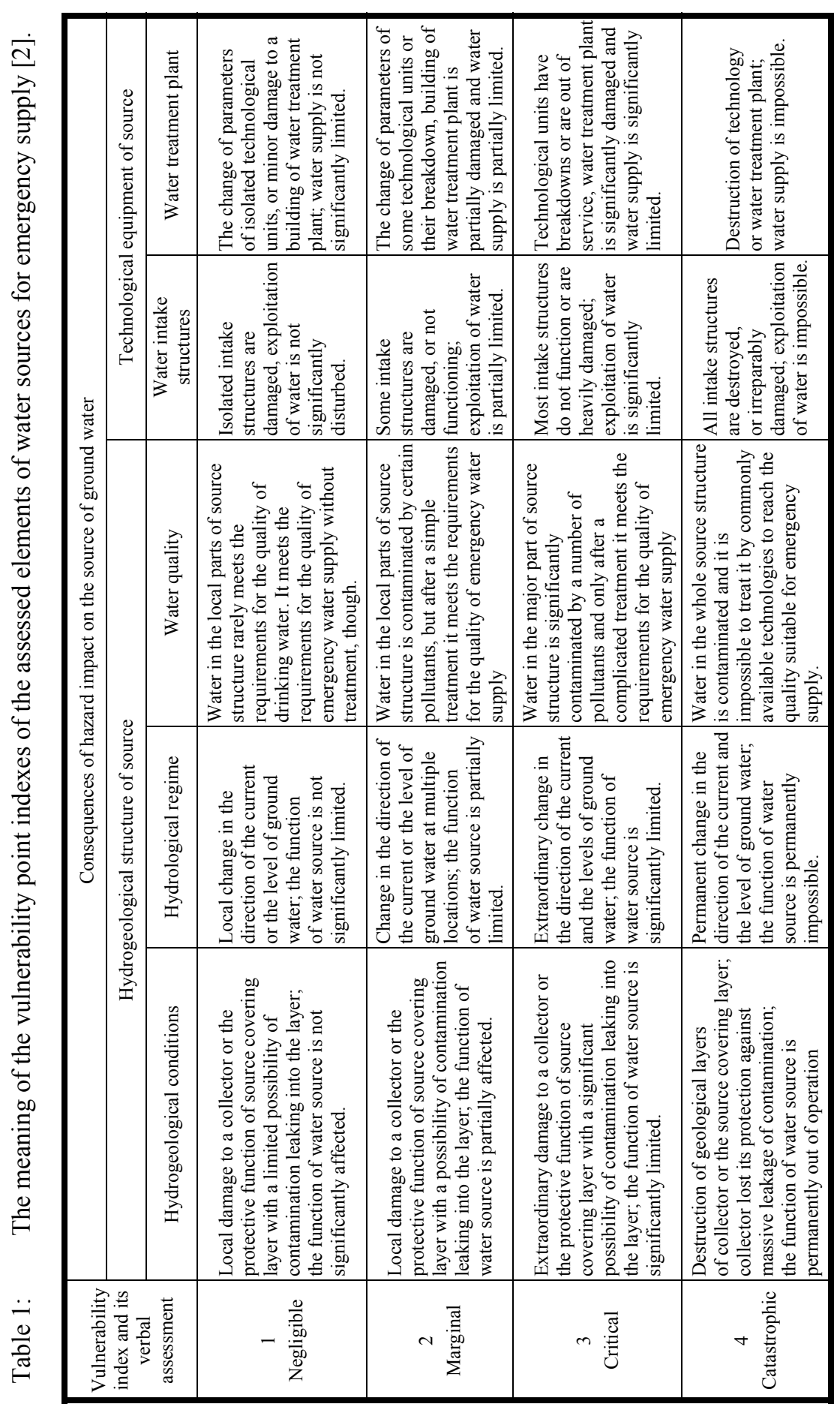

WIT Transactions on Ecology and The Environment, Vol 162, (c) 2012 WIT Press www.witpress.com, ISSN 1743-3541 (on-line) 
A short-term cut-off of water intake in the case of fall-out of electric current may temporarily put the water intake structure out of operation. Damage or destruction of electro-installation will cause a long-term cut off of water intake from water intake installation and will not make the water supplies within the emergency water supply possible. The sensitivity of the system in relation to the assessed hazard is reduced by installing the protection against lightning. A shortterm cut-off of water intake from the water intake structure will result in the temporary outage of the source of emergency water supply. Its functionality will not be disturbed and may be put into operation again when the supplies of electric current are operational. The long-term cut-off of water intake from the water intake structure would lead to the disturbance of the network of emergency water supply facilities and the necessity to supply population from another source.

Neither short nor long interruption of supply of electric current in the water treatment plant would put the selected source of emergency water supply out of service in the case the untreated water met the parameters of water for emergency water supply. In the opposite case the situation could be solved by employing an alternative source of energy and a mobile water treatment plant.

With regard to the above mentioned facts the water intake structure (WIS) vulnerability index is 2 and the water treatment plant (WTP) vulnerability index is 1 .

\subsection{Hailstorms and torrential rains}

Only the technical equipment of emergency water supply source is vulnerable to hailstorms and torrential rains. The building of armature chamber and WTP may be flooded, which could lead to the damage, or destruction of WIS or the equipment of WTP.

The WIS is located in a brick building, which is built on the level of terrain and is equipped with double water-proof doors. The water intake would not be disturbed in the case the hazard was activated. The hazard will not affect the function and utilization of WIS.

The vulnerability of WTP technological equipment is minimized by its location in the brick building, which is heightened and secured by double waterproof doors. The process of water treatment should not be disturbed. In exceptional cases of disturbance the problem could be solved similarly to the damage caused by the struck of lightning.

The WIS vulnerability to hailstorms and torrential rains has been assessed by index 1 and the WTP vulnerability index is also 1 .

\subsection{Extreme and long-lasting precipitation}

Both hydrological structure and technical equipment of the source of emergency water supply are vulnerable to extreme and long-lasting precipitation. 
Infiltration of a large amount of surface water in the infiltration area of the assessed drill hole may lead to an extreme increase of ground water level and consequently to the changed gradient of piezometric level of ground water with impact on the velocity and direction of ground water flow.

The building of armature chamber and WTP may be flooded, which could lead to the damage or destruction of WIS or the equipment of WTP and result in unsatisfactory quality of supplied water. The WIS and WTP vulnerability assessment is the same as in the case of hazards caused by hailstorms and torrential rains.

The vulnerability of all the above mentioned elements of source to the hazards caused by extreme and long-lasting precipitation has been assessed by vulnerability index 1 .

\subsection{Fires of natural origin}

Fires of natural origin may be caused by storms and other electric phenomena. The above mentioned hazard may threaten the technological equipment of the source of emergency water supply, i.e. WIS and WTP.

The buildings are constructed in such a way that their vulnerability to flare up is minimal.

The buildings may catch fire from the burning trees and bushes, which grow in the surrounding area and inside the fenced waterworks facility. Fire may cut off, damage, or destroy electroinstallation, which may result in the situation similar to the one caused by storms and electric phenomena. Fire may destroy the construction of WIS and WTP, which would lead to a long-lasting elimination of drill hole and the utilization of the source of emergency water supply would be stopped.

The WIS vulnerability to the fires of natural origin has been assessed by vulnerability index 3 , in the case of WTP the index is 1 .

\subsection{Windstorms and wind gusts}

Technical equipment of the source of emergency water supply is vulnerable to windstorms and wind gusts, which may damage the roof constructions of buildings. Windstorms and wind gusts may also uproot (or break) the trees, which may fall on the buildings and either damage their roofs and statics, or destroy them completely.

Minor damage to the statics of buildings will not affect water intake from the water intake structure and its further treatment. Serious damage of WIS will put the source of emergency water supply out of service. The destruction of WTP will not affect the operation of the source of emergency water supply.

The WIS vulnerability to the windstorms and wind gusts has been assessed by vulnerability index 2 , in the case of WTP the index is 1 . 


\subsection{Floods}

Floods caused by the increased water level of nearby creek may lead to the damage or destruction of WIS and the equipment of WTP. The facilities may be wet from floods and their statics may be affected by that. Wet construction components may result in the black-out of electric installation and electronic equipment in the facilities. Although the WIS is secured by double water-proof doors, flood could damage them. Thus the ground water intake could be disturbed due to possible leakage of contaminated surface water into the drill hole. The hazard will shortly affect the function and utilization of WIS. The WTP could be put out of service in the same way. In such cases it would not be possible to use water from the given source for emergency water supply.

For the above mentioned reasons the vulnerability index of both elements of the technological equipment of the source has the value 4 .

\subsection{Soil erosion}

Only the technical equipment of the source of emergency water supply is vulnerable to soil erosion. Fence with $50-\mathrm{cm}$ concrete pedestal around the water intake zone prevents the fertile topsoil from the surrounding farmland to be washed away toward the WIS and WTP. Therefore both the WIS and WTP vulnerabilities to soil erosion have been assessed by vulnerability index 1 .

\subsection{Leakage of gases from the earth's interior}

The increased leakage of gases from the Earth's interior may affect only the quality of ground water. The activation of this source of hazard will affect the concentration of radionuclides in ground water, which consequently need not meet the requirements for the quality of water for emergency supply. If the concentration of radionuclides is over the limit permissible for the emergency water supply, it is necessary either to put the source out of operation, or to implement adequate water treatment procedures with the aim to reach the permissible concentrations of radioactive pollutants. The process of reducing the concentration of radioactive pollutants from the monitored source is technologically complicated and expensive.

The vulnerability of ground water quality to the leakage of gases from the Earth's interior has been assessed by vulnerability index 3 .

\subsection{Increased radioactive background}

The increased radioactive background may have a negative impact on water quality. The infiltration territory of the source is known as the area with increased radioactive background. The outcomes of chemical analyses show that the content of radon meets the valid legal standards. The vulnerability assessment considered the fact that the accompanying effect of increased radioactive background is the gas leakage from the Earth's interior. Such a hazard could have a significant impact on water quality for a long period of time. 
Meeting the water quality standards for a short-term emergency supply would require the implementation of adjustments aimed at reducing the concentrations of radionuclides below the limit values.

The vulnerability of ground water quality to the hazard of increased radioactive background has been assessed by vulnerability index 3 .

\subsection{Fires of anthropogenic origin}

Fires of anthropogenic origin in the area may be caused by careless manipulation with open fire and smoking. Impacts identical with the impacts of fires of natural origin. Therefore the vulnerability index of WIS is 3 and the vulnerability index of WTP is 1 .

\subsection{Husbandry and forestry}

Both WIS and WTP are vulnerable to husbandry and forestry. Due to favourable geological conditions in the infiltration area of the assessed drill it can be assumed that the leakage of fuels and other operation fluids and the substances protecting, nourishing and stimulating the growth of plants, cannot have an impact on the quality of water. Careless handling of agricultural vehicles may result in the damaged fence of the facility. It will not have a significant impact on the technological equipment of the source. If the vehicles hit the brick buildings, either statics may be disturbed, or the buildings may be destroyed. Minor static disturbance of buildings will not affect water intake from the WIS and its further treatment. Serious damage of WIS will put the source of emergency water supply out of service. The destruction of the WTP building will not limit the operation of the source of emergency water supply, because it may be replaced by a mobile water treatment plant.

The vulnerability of WIS to the hazard of husbandry and forestry has been assessed by vulnerability index 2 , in the case of WTP the index is 1 .

\section{Conclusion}

The practical applicability of the proposed procedure of semi-quantitative assessment of vulnerability of the threatened elements of hydrogeological structure and technological equipment of the source of ground water has been verified. The outcomes in the form of the register of hazards, together with the point values of vulnerability indexes for the threatened elements of the assessed water source potentially exploitable for the emergency supply of population with drinking water, are presented in the Table 2.

The point values of vulnerability indexes are the basis for assessing the risks of disturbance, damage, or destruction of water source by the identified hazards and consequently for determining the critical risks. Risk assessment should become one of the significant criteria for classifying water sources suitable for emergency supply of population with drinking water. Proper classification of ground water sources is necessary for their efficient selection and incorporation into crisis plans with the aim to enhance the readiness of regions for possible 
Table 2: $\quad$ Register of potential hazards and values of vulnerability indexes for the threatened elements of the assessed ground water source HGChydrogeological conditions; HR-hydrological regime, WQ-ground water quality; WIS-water intake structures; WTP-water treatment plant.

\begin{tabular}{|c|c|c|c|c|c|}
\hline \multirow{2}{*}{ Register of hazards } & \multicolumn{5}{|c|}{ Values of vulnerability indexes } \\
\cline { 2 - 6 } & HGC & HR & GWQ & WIS & WTP \\
\hline Storms and other electric effects & - & - & - & 2 & 1 \\
\hline Hailstorms and torrential rains & - & - & - & 1 & 1 \\
\hline Extreme and long-lasting precipitation & - & 1 & - & 1 & 1 \\
\hline Fires of natural origin & - & - & - & 3 & 1 \\
\hline Windstorms and wind gusts & - & - & - & 2 & 1 \\
\hline Floods & - & - & - & 4 & 4 \\
\hline Soil erosion & - & - & - & 1 & 1 \\
\hline Leakage of gases from the Earth's interior & - & - & 3 & - & - \\
\hline Increased radioactive background & - & - & 3 & - & - \\
\hline Fires of anthropogenic origin & - & - & - & 3 & 1 \\
\hline Husbandry and forestry & - & - & - & 2 & 1 \\
\hline
\end{tabular}

states of crisis connected with the broken supply of drinking water in crisis situations.

\section{Acknowledgement}

The outcomes presented in this contribution are part of the security research project on "The Methodology of Assessing the Sources of Emergency Water Supply on the Basis of Risk Analysis". The project No is VG20102013066 and the project is financed by the Ministry of Interior of the Czech Republic.

\section{References}

[1] Bozek, F., Dvorak, J., Caslavsky, M. Sources for Emergency Water Supply I. Hazard Identification. In Demiralp, M., Bojkovic, Z., Repanovici A. (Eds.). Mathematical Methods and Techniques in Engineering and Environmental Science. Proceedings of the $4^{\text {th }}$ WSEAS International Conference on Natural Hazards (NAHA'11). Catania: WSEAS Press, 2011, pp. 85-90. ISBN 978-1-61804-046-6.

[2] Bakos, E., Bozek, A., Caslavsky, M., Bozek, F. Emergency Water Supply II. Vulnerability of Particular Selected Water Resource. In Niola, V., Ng, K. (Eds.). Recent Researches in Chemistry, Biology, Environment and Culture. Proceedings of the $9^{\text {th }}$ WSEAS International Conference on 
Environment, Ecosystems and Development(EED'11). Montreux: WSEAS Press, 2011, pp. 17-21. ISBN 978-1-61804-060-2.

[3] Ministry of Agriculture of the Czech Republic (MoA CR). Typified plan Disruption of Drinking Water Supplying in Major Extent. Prague: MoA CR, 2004.

[4] Ministry of Agriculture of the Czech Republic (MoA CR). MoA Directives for standardized procedures to be followed by the authorities of regions, capital of Prague, municipalities and Prague urban districts in order to provide population with emergency supply of drinking water under emergencies and states of crises with the help of Emergency Water Supply Service. Government Bulletin for the Authorities of Regions and Municipalities, Vol. 9, Article 3, 2011, pp. 42-46.

[5] National Institute of Public Health (NIPH). Emergency Drinking Water Supply. Methodical Recommendation of NIPH - National Referential Centre for Drinking Water. Prague: NIPH, 2007.

[6] U.S. EPA. Drinking Water Standards and Health Advisories Tables. Washington DC: U.S. EPA, 2009. [on line]. [2012-04-07]. URL: $<$ http://www.epa.gov/waterscience/criteria/drinking/dwstandards.pdf $>$

[7] Ministry of Agriculture of the Czech Republic (MoA CR). MoA Methodical Guidelines for the Selection and Maintenance of Sources for Emergency Water Supply. MoA CR Bulletin, 2002, article 3, pp. 1-10.

[8] Božek, F., Urban, R. Risk Management. 1st ed. Brno: University of Defence, 2008. 145 p. ISBN 978-80-7231-259-7.

[9] Gogu, R. C., Dassargues, A. Current Trends and Future Challenges in Groundwater Vulnerability Assessment Using Overlay and Index Methods. Environmental Geology, 2000, vol. 39, no. 6, pp. 549-559.

[10] Bumbova, A., Bozek, F., Caslavsky, M., Dvorak, J. The Identification of Threats to the Source of Emergency Water Supply. In ESREL 2012 Conference, Helsinky, 2012, 9 p. [In print].

[11] Warner, M. L. - Preston, E. H. A Review of EIA Methodologies. Washington, D.C.: U.S. EPA, 1974.

[12] Wells, G. Major Hazards and their Management. $1^{\text {st }}$ Ed. Rugby: The Institution of Chemical Engineers, 1997. ISBN 0-85295-368-2.

[13] Fishburn, P.C. Utility Theory for Decision-Making. $1^{\text {st }}$ Ed. New York: J. Wiley and Son, 1970. 